Gut, 1963, 4, 406

\title{
Correlation of manometric, oesophagoscopic, and radiological findings in the columnar-lined gullet (Barrett syndrome)
}

\author{
B. R. COHEN, B. S. WOLF, M. SOM, AND H. D. JANOWITZ \\ From the Division of Gastroenterology of the Department of Medicine and the Departments \\ of Otolaryngology and Radiology, The Mount Sinai Hospital, New York, N.Y.
}

EDITORIAL SYNOPSIS An intensive study has been made of the columnar-lined gullet (Barrett syndrome) and in the patient described it was shown to have the motor characteristics of the body of the oesophagus. At the distal end there was the normal receptive relaxation with swallowing. There was no discontinuity between the squamous and the columnar-lined portions.

In 1950, Barrett (1950) pointed out that cases reported as 'chronic peptic ulcer of the oesophagus' occurred in columnar epithelium which surrounded the ulcer and extended for a considerable distance proximal to the cardia in a continuous sheath of 'heterotopic epithelium'. This columnar epithelium resembled that of the cardiac portion of the stomach and contained a variable number of parietal cells. In his original report, Barrett suggested that the columnar-lined segment was an attenuated thoracic stomach associated with a congenitally short oesophagus. Allison and Johnstone (1953) subsequently reported a group of similar patients in whom operation had been performed. On the basis of the arterial supply and the peritoneal reflections found at operation, these authors suggested that the intermediate columnar-lined segment was oesophagus in all features except its lining epithelium. They also noted the association of a typical sliding hiatal hernia with reflux in all of their patients. Ulcerations of both a superficial and a deep character were noted in the columnar-lined segment. Allison and Johnstone suggested the possibility that the columnar epithelium might not be of congenital origin but rather in the nature of replacement epithelium secondary to reflux oesophagitis. In a later report, Barrett (1960) agreed that the intermediate columnar-lined segment was probably oesophagus and stated that 'the abnormal segment is neither true stomach nor oesophagus and that how it may behave physiologically or pathologically is impossible to predict'. Since these original descriptons of the 'Barrett syndrome', there have been several reports of patients with this condition (Allison and Johnstone, 1953; Som and
Wolf, 1956; Goldman and Beckman, 1960; Moersch, Ellis, and McDonald, 1959) but there is no unanimity of opinion as to its pathogenesis.

While the nature of the epithelium lining the intermediate segment is clear from these reports, there is little information as to the motor behaviour of the columnar-lined segment. Motility studies of the columnar-lined segment should indicate whether it behaves as oesophagus or stomach but such an account is lacking in the literature. Since this condition is relatively uncommon, the opportunity to perform such studies arises infrequently. This opportunity was, however, presented to us by a patient who appeared with a typical history and radiological findings of the Barrett syndrome who was then investigated by oesophagoscopy, biopsy, and manometric methods. This report summarizes the results of these combined studies.

The patient was a 68-year-old male elevator operator admitted with the chief complaint of dysphagia. A history of intermittent heartburn starting at the age of 19 was elicited. At the age of 39 the patient experienced an episode of recurrent vomiting lasting several weeks the cause of which was never determined. Nocturnal episodes of heartburn and retrosternal pain started at about the age of 50. Approximately nine months before admission, the nocturnal retrosternal pain increased in severity and frequency. This pain occurred characteristically on recumbency, was transiently relieved by antacids, and occasionally associated with radiation of pain to the back, burning epigastric pain, and inability to swallow solid food. Soft foods and liquids could be swallowed without difficulty. The patient lost $20 \mathrm{lb}$. in weight and was admitted to the hospital for evaluation. 


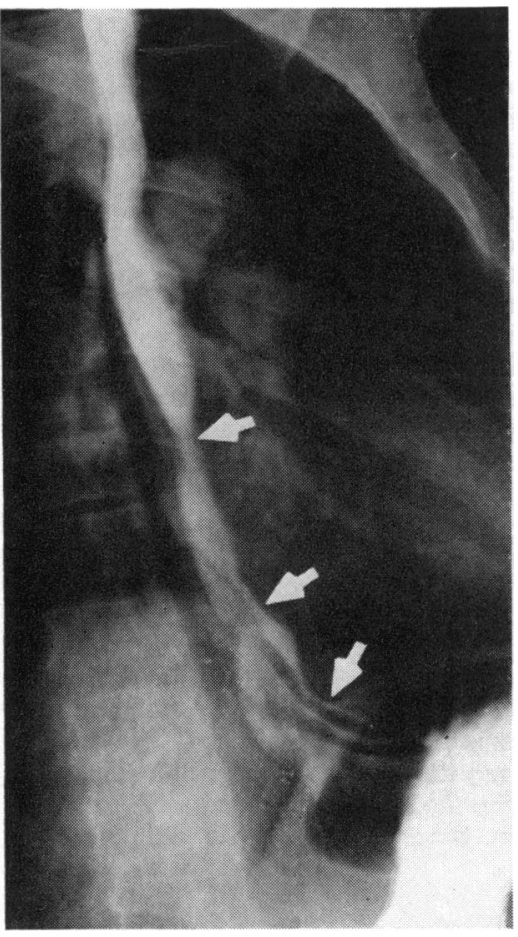

FIG. 1A

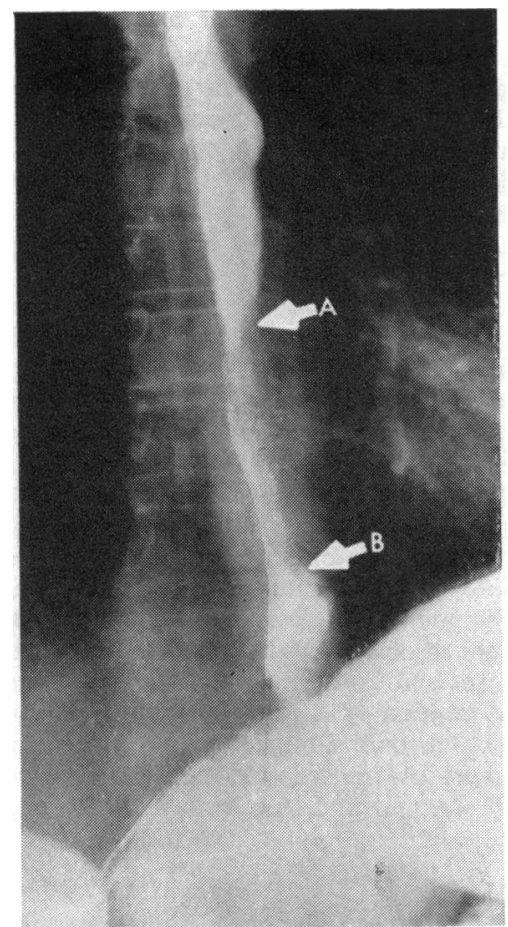

FIG. 1B

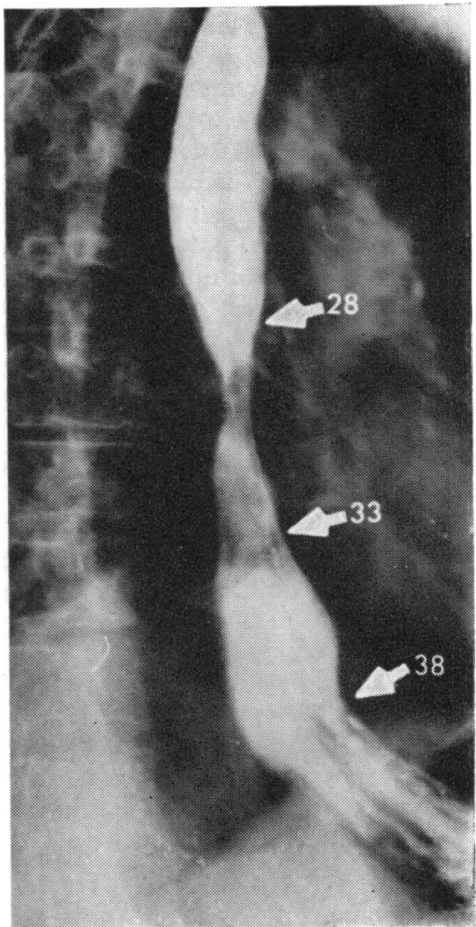

FIG. 1C

FIG. 1A. Right anterior oblique view with the patient prone shows a short tapering stenotic area just below the midportion of the thoracic oesophagus (upper arrow). The 'gullet' distal to this is incompletely distended on this film. The hiatus (lower arrow) is wide. A short distance above the hiatus (middle arrow) there is a relative area of narrowing between a small saccular stricture distally (between lower and middle arrows) and a triangular segment proximally (between upper and middle arrows). Folds with the appearance of gastric rugae extend from the fundus of the stomach upward through the hiatus.

FIG. 1B. A film taken in the antero-posterior projection with the patient supine shows a 'spastic' contraction extending from the mid-portion of the oesophagus to the saccular structure located above the hiatus (from arrow $A$ to arrow $B$ ).

FIG. 1C. A film taken in the right anterior prone oblique position during the course of manometric studies. With maximum distension, it is evident that the proximal half of the oesophagus is unusually distensible. The portion of the gullet distal to the site of stenosis shows an elongated triangular configuration with broad base distally. The barium extends through a widened hiatus into the infradiaphragmatic portion of the stomach. Thick folds in the region of the hiatus are not effaced despite distension. A polyethylene assembly of three tubes is in situ within the gullet. The recording openings of the three tubes are indicated by metallic clips. The proximal opening (upper arrow) was located $28 \mathrm{~cm}$. from the incisor teeth, above the short stenotic area. The middle opening (arrow 33) was located approximately in the mid-portion of the intermediate or transitional segment. The distal opening (arrow 38) was located a short distance above the hiatus corresponding approximately to the upper margin of the rugal pattern.

On examination, the patient appeared chronically ill with evidence of recent weight loss but no other significant physical findings. Transient confusion and loss of recent memory suggested the presence of an organic mental syndrome presumably on the basis of cerebral arteriosclerosis.

Laboratory findings included a haemoglobin of $9.6 \mathrm{~g}$. per $100 \mathrm{ml}$., white cell count of 7,150 per c.mm., a normal differential count and normal sedimentation rate of $51 \mathrm{~mm}$. (Westergren) in one hour. Blood urea nitrogen, fasting blood sugar, alkaline phosphastase, SGOT, and serum calcium were within normal limits. The stool examinations gave a $4+$ reaction on guaiac testing. Sigmoidoscopic examination was negative. An electrocardiogram was interpreted as within normal limits.

Radiological examination of the oesophagus (Fig. 1) showed findings highly suggestive of the Barrett syndrome. A short distance below the mid-portion of the thoracic oesophagus there was a stenotic area about $1 \mathrm{~cm}$. in length which failed to distend completely at any time during the 
examination. This area showed a smooth, tapering configuration both proximally and distally and did not appear to be rigid or ulcerated. The oesophagus proximal to this level was slightly more distensible than normally. The 'gullet' distal to this area of stenosis and extending down to the level of the hiatus showed an elongated, triangular configuration when maximally distended. When partially filled, the distal portion of this region showed thick folds which appeared to be continuous with typical gastric rugae extending into the stomach. The hiatus was obviously widened and at times there was a suggestion of a small saccular dilatation about $2 \mathrm{~cm}$. in length immediately above the level of the hiatus. Occasionally during the radiological observations, the segment between the narrowed area in the mid-oesophagus and the small sac distally appeared to contract in a fairly uniform and spastic fashion. The stomach was of normal appearance. The duodenal bulb was deformed but an ulcer crater could not be demonstrated. The radiological interpretation was that of a benign stenosis in the mid-oesophagus presumably due to inflammatory changes associated with the Barrett syndrome. The widened hiatus and from time to time the appearance of a small sac containing rugae above the hiatus indicated the presence of a small sliding hiatus hernia. However, the exact level of transition between the suspected columnar-lined segment and the hiatus hernia could not be determined.
With the radiological findings in mind, oesophagoscopy was performed with the intention of performing biopsies at multiple levels to determine the nature of the lining epithelium. The proximal oesophagus for a distance of 29 $\mathrm{cm}$. from the incisor teeth appeared entirely normal. At this level, however, the epithelium became reddened and slightly oedematous and the lumen narrowed. With pressure on the oesophagoscope, however, this narrowed region could be traversed with little difficulty. Distal to the narrowed segment, the mucosa was reddened with scattered superficial ulcerations. A more prominent, somewhat longitudinal, superficial, linear ulceration was seen extending from 35 to $37 \mathrm{~cm}$. from the incisor teeth. Rather marked narrowing of the lumen was encountered at the site of this longitudinal ulceration which required bouginage before the oesophagoscope could be passed any further. At $38 \mathrm{~cm}$. distinct gastric rugae were observed which did not appear to be inflamed and at this point there was evidence of free reflux of gastric contents. Biopsies were taken at 28,35 , and $38 \mathrm{~cm}$. from the incisor teeth. The first biopsy was taken a short distance above the proximal narrowed segment from normal-appearing squamous epithelium, the second biopsy within the inflamed segment adjacent to ulceration, and the third biopsy from apparently normal gastric rugae. The biopsy taken at $29 \mathrm{~cm}$. (Fig. 2A) showed normal uninflamed squamous epithelium. Biopsy at $35 \mathrm{~cm}$. (Fig. 2B) within

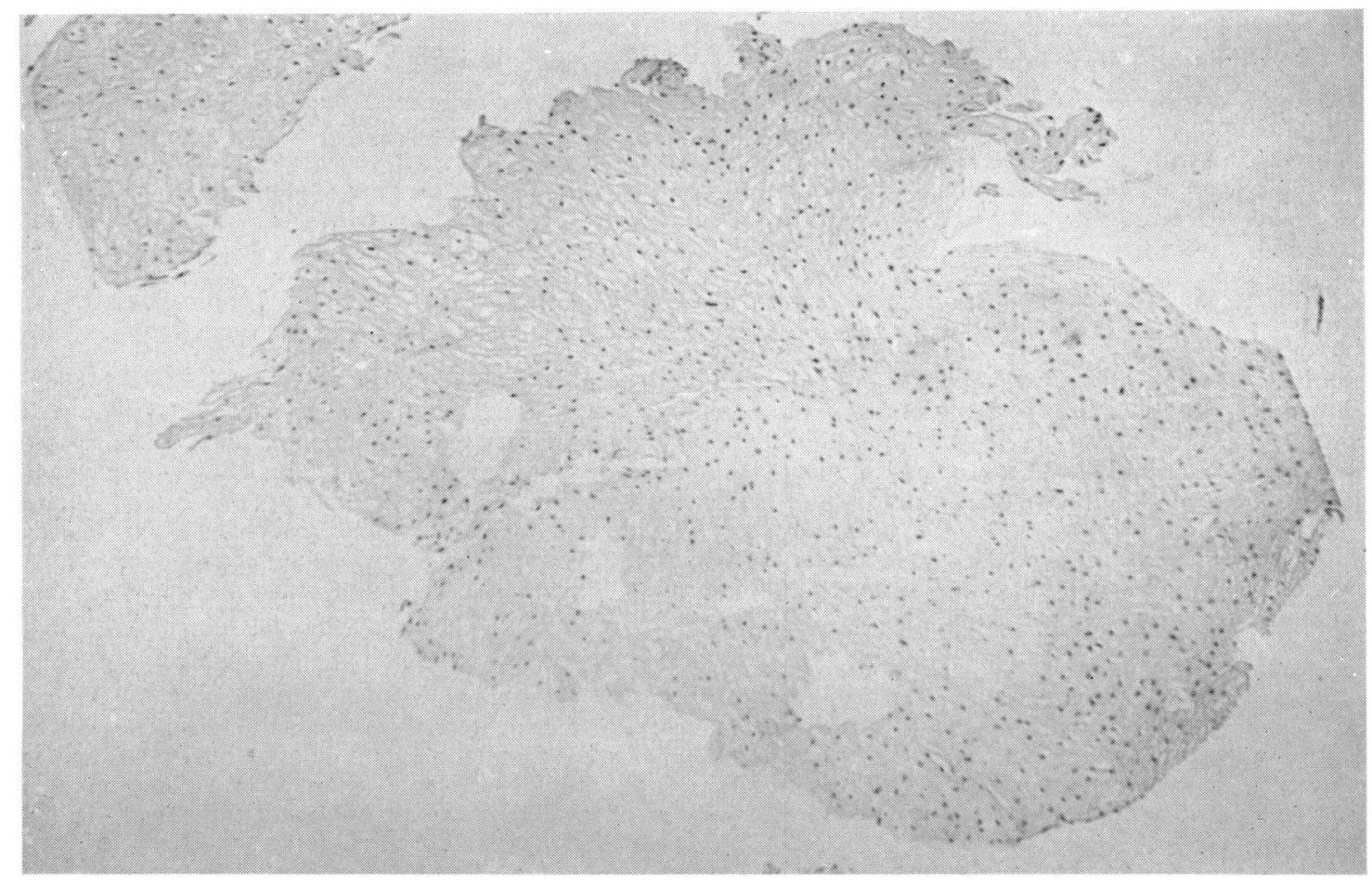

FIG. 2A. Biopsy taken at about $28 \mathrm{~cm}$. above the narrowed segment in the mid-oesophagus (Fig. 1C) shows normal uninflamed squamous epithelium. 


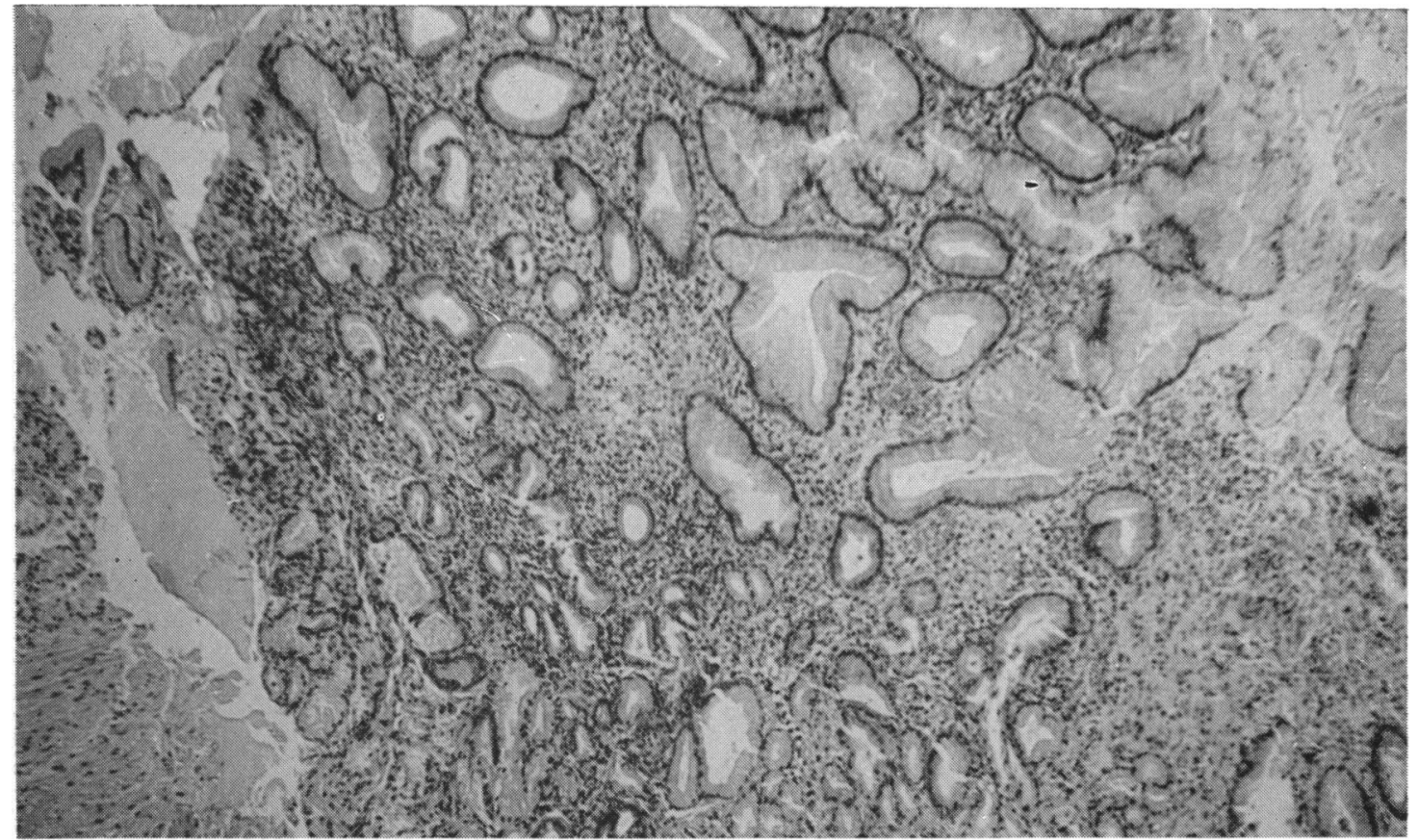

FIG. 2B. Biopsy taken $35 \mathrm{~cm}$. from the incisor teeth adjacent to ulceration demonstrates the typical Barrett type of epithelium. Columnar epithelium with many mucous cells and a marked inflammatory reaction in the mucosa and submucosa are present.

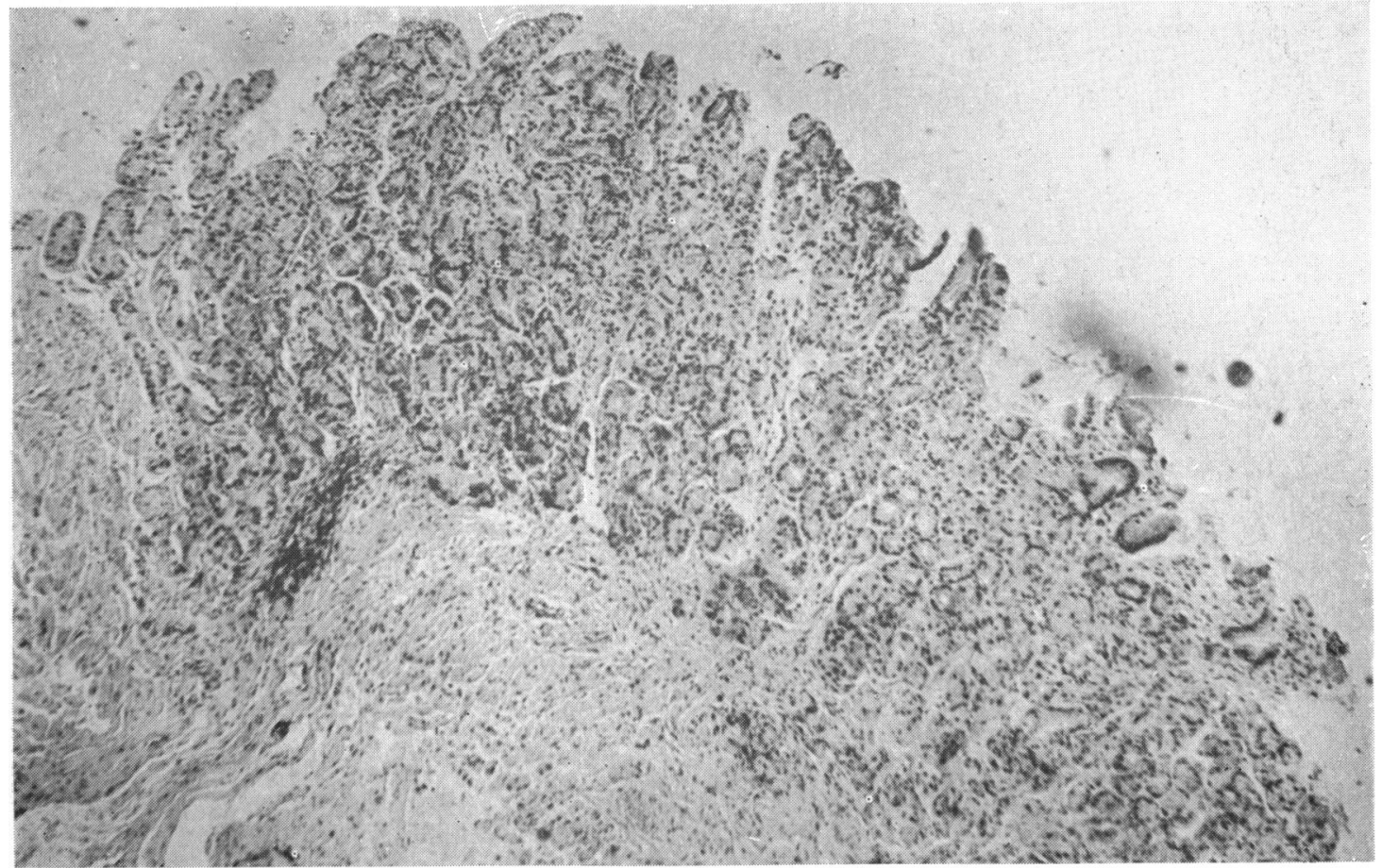

FIG. 2C. At $38 \mathrm{~cm}$. from the incisor teeth, the biopsy shows gastric epithelium with glandular pit formation. Occasional parietal cells were evident at higher magnification. 
the intermediate segment showed columnar-epithelium with a marked inflammatory response in the mucosa and submucosa. Mucous cells were prominent but parietal cells were absent. Biopsy taken at $38 \mathrm{~cm}$. (Fig. 2C) showed normal gastric epithelium with prominent pits of glandular columnar epithelium resembling the glands of the cardia. Mucous cells were present at the neck of these glands, chief cells at the base, and occasional parietal cells were scattered through the mid-portion of the glands.

The radiological and histological findings were those of the Barrett syndrome, i.e., radiologically, a tubular structure with a high-lying stricture, squamous epithelium above the stricture, and gastric-like epithelium below it. Motility studies were therefore performed to determine whether all or only part of this tube behaved physiologically like the oesophagus. This was done by standard techniques using an assembly of three polyethylene catheters with recording openings positioned $5 \mathrm{~cm}$. apart. The distal end of each opening was marked with a radioopaque clip and the patient studied in the prone right anterior oblique position to facilitate radiological locali-
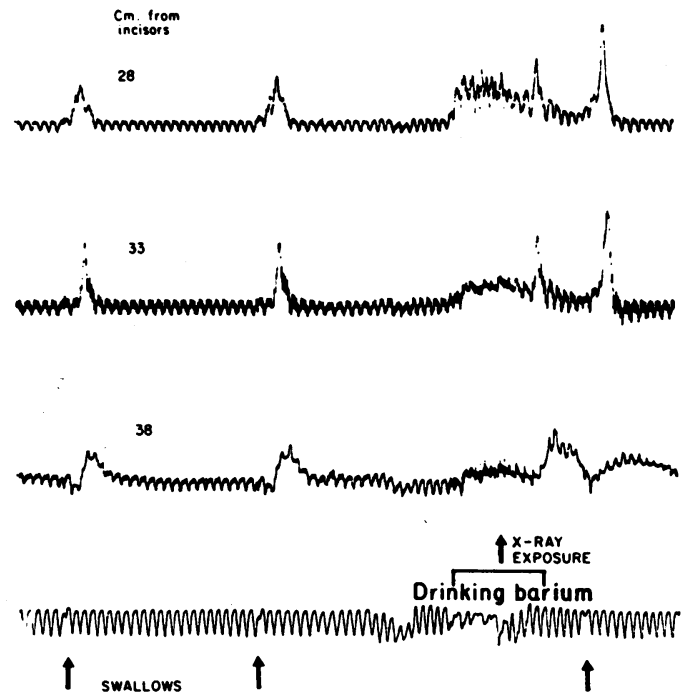

FIG. 3. Example of pressure record during the course of barium swallow and $\mathrm{x}$-ray exposure taken to localize the sites of the recording lumina in relationship to radiological features. The polyethylene assembly was positioned with the openings as indicated in the upper three tracings, that is, 28 , 33 , and $38 \mathrm{~cm}$. from the incisor teeth. The lowest tracing is from the pneumograph arranged to indicate inspiration by $a$ downward deflection. The patient was directed to drink the fluid barium mixture continuously and an x-ray exposure taken and recorded during the course of drinking as indicated in the latter portion of the tracings. The vertical arrows indicate single dry swallows and the bracket indicates the period of drinking of the barium. The time of the x-ray exposure was obtained by relay of the x-ray exposure signal into the time marker of the oscillograph. The identity of the tracings before and after swallowing indicates no change in the location of the catheter assembly. zation of the recording sites. The catheters were positioned with all openings in the stomach below the diaphragm and then gradually withdrawn proximally. Resting and swallowing pressures were recorded at appropriate intervals. Radiographs of the barium-filled oesophagus (Fig. 3) were obtained with simultaneous recording of intraluminal pressures (Wolf and Cohen, 1961).

With the three recording openings positioned at 28, 33, and $38 \mathrm{~cm}$. from the incisor teeth (Fig. 1C), there was no difficulty in demonstrating a continuous peristaltic wave during a dry swallow (Fig. 4). The opening at $28 \mathrm{~cm}$. was definitely above the narrowed segment on radiological examination, that is, in the normal squamous-lined portion of the oesophagus. The opening at $33 \mathrm{~cm}$. was approximately in the middle of the intermediate columnarlined segment. The opening at $38 \mathrm{~cm}$. was about $2 \mathrm{~cm}$. above the hiatus. The traces at 28 and $33 \mathrm{~cm}$. were typical of those obtained from the body of the oesophagus. The trace from the most distal opening at $38 \mathrm{~cm}$. was of particular interest because, before the appearance of the

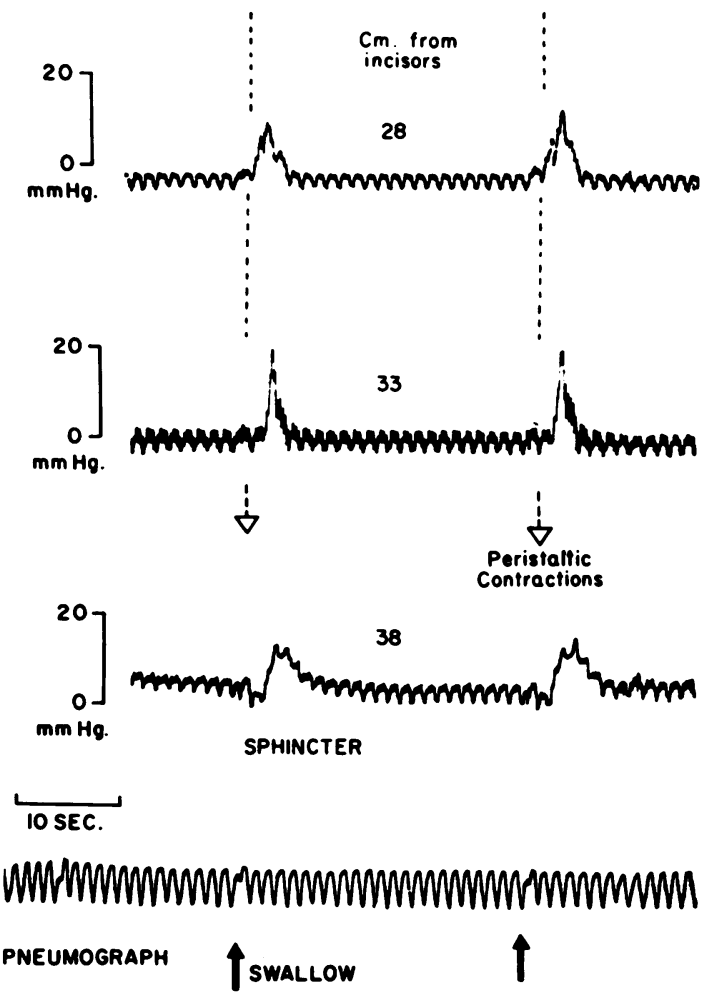

FIG. 4. Pressure tracings taken at sites indicated in the radiograph of Fig. 1C. These tracings demonstrate continuous peristaltic contractions through the squamous and columnar-lined portions of the gullet. The pressure tracing taken at $38 \mathrm{~cm}$. from the incisor teeth shows minimal but distinct receptive relaxation and a more prolonged peristaltic response of lower amplitude than the openings above. This type of response to swallowing is characteristic of the 'sphincteric' area. The resting pressure in this area is somewhat greater than the resting pressures above. 


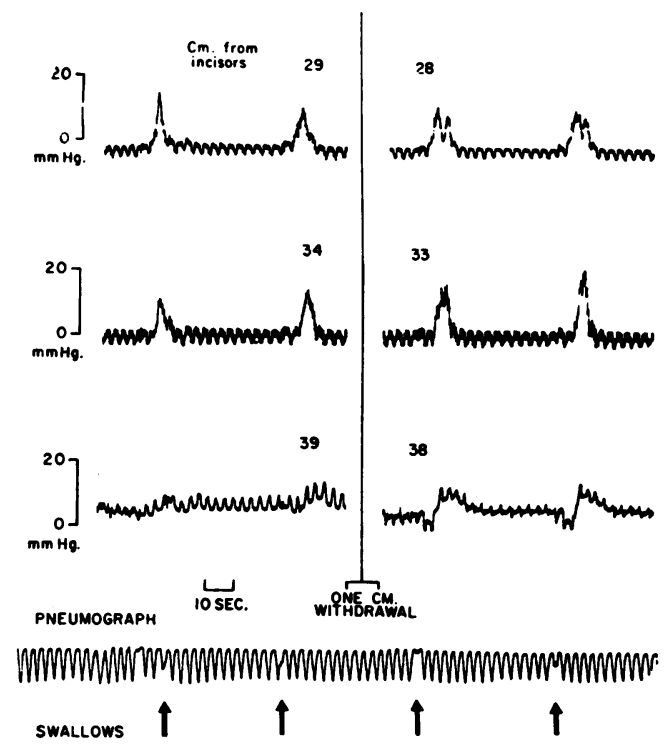

FIG. 5. Pressure tracings during a 'pull-through' study in which the distal recording opening was withdrawn from 39 $\mathrm{cm}$. to $38 \mathrm{~cm}$. in order to demonstrate the oesophagogastric junction. The response obtained at $39 \mathrm{~cm}$. on swallowing consists of a meagre increase in pressure which was also seen from recordings made more distally in the stomach. After withdrawal of the polyethylene assembly $1 \mathrm{~cm}$. proximally so that the distal opening was at $38 \mathrm{~cm}$., the tracing at $38 \mathrm{~cm}$. showed receptive relaxation followed by peristaltic contraction. The response to inspiration at $39 \mathrm{~cm}$. was negative and at $38 \mathrm{~cm}$. biphasic. The resting pressure at $39 \mathrm{~cm}$. was essentially the same as at $38 \mathrm{~cm}$.

peristaltic wave, there was a distinct negative wave of anticipatory or receptive relaxation. Moreover, the peristaltic positive wave at this level was of smaller amplitude and longer duration than was recorded from the two openings above. These phenomena are characteristic of the 'sphincteric area' in the terminal oesophagus. Further information as to the nature of the segment at $38 \mathrm{~cm}$. was obtained by comparing the pressures at this site with those immediately below at $39 \mathrm{~cm}$. from the incisor teeth. The record at $39 \mathrm{~cm}$. (Fig. 5) showed a slight somewhat sustained increase of pressure on swallowing. This response was interpreted as gastric in nature since it did not resemble an oesophageal complex and was also obtained at more distal levels. This finding confirmed the impression that the oesophago-gastric junction was located between 38 and $39 \mathrm{~cm}$. from the incisor teeth. The intraluminal pressure at $39 \mathrm{~cm}$. increased with inspiration and at $38 \mathrm{~cm}$. was biphasic. In the presence of a small sliding hernia, these changes with respiration are not reliable indicators of the level of the hiatus. No evidence of any sphincteric activity was recorded below the point of respiratory reversal, suggesting that the oesophagus did not extend through the hiatus and that a small hiatus hernia was present.

Resting or basal pressures at various sites during the
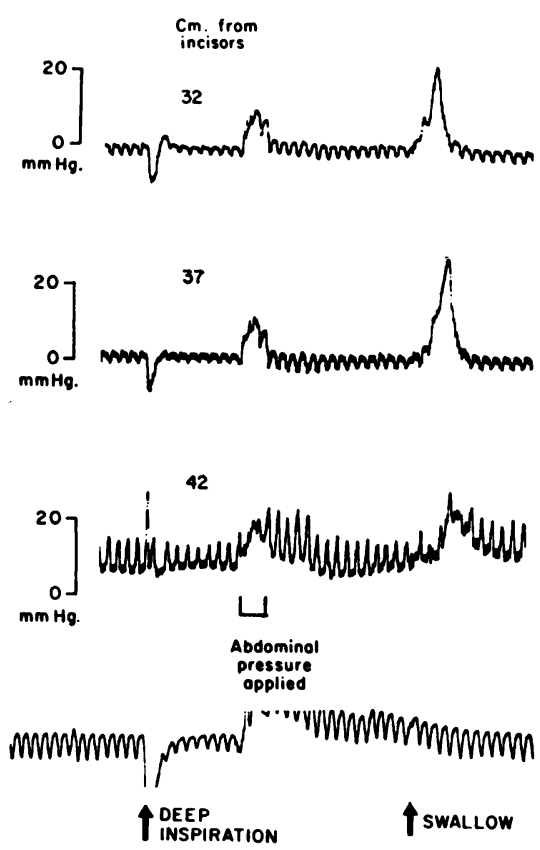

FIG. 6. Response of gastric and oesophageal intraluminal pressures to externally applied increases in pressure. In this record, the distal recording lumen is well within the stomach while the proximal two openings are in the oesophagus. Pressure applied by the examiner's hand to the upper abdomen during the interval indicated by a bracket below the third tracing produced equal simultaneous and sustained pressure increases in the stomach and in the oesophagus.

'pull-through' study showed $+5 \mathrm{~mm}$. $\mathrm{Hg}$ in the fundus of the stomach, $+5 \mathrm{~mm}$. $\mathrm{Hg}$ in the 'sphincteric' area, and, in the columnar-lined segment, a gradual fall proximally to $-4 \mathrm{~mm} . \mathrm{Hg}$. As pointed out above, the presence of receptive relaxation and a prolonged contraction of relatively low amplitude at $38 \mathrm{~cm}$. from the incisor teeth served to identify the 'sphincteric' area at the distal end of the columnar-lined segment. The resting pressures, however, failed to show the usual increase in the 'sphincteric' area as compared with the stomach although pressure in this area was greater than in the more proximal oesophagus. These features are consistent with the presence of a small hiatal hernia and interference in the normal function of the sphincter (Atkinson, Edwards, Honour, and Rowlands, 1957; Texter, Lazar, Puletti, and Van trappen 1959). The absence of the normal anti-reflux mechanism was confirmed by a manoeuvre designed to demonstrate free transmission of intraluminal pressures from stomach to oesophagus. With a catheter assembly positioned so that the recording lumens were 42,37 , and $32 \mathrm{~cm}$. from the incisor teeth, the effect of increasing intra-abdominal pressure upon intrafundic and intra-oesophageal pressures were noted. Gradually increasing firm pressure upon the left upper quadrant of the abdomen by the examiner's hand caused an immediate equal and sustained pressure 


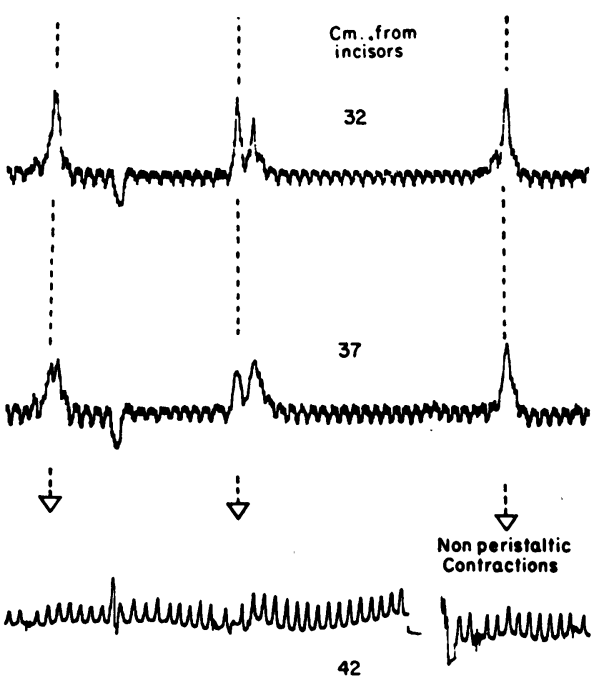

PNEUMOGRAPH

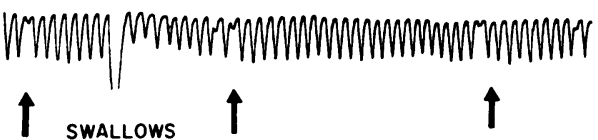

FIG. 7. Record taken with the proximal two openings in the columnar-lined portion of the stomach shows non-peristaltic, at times repetitive, swallowing responses.

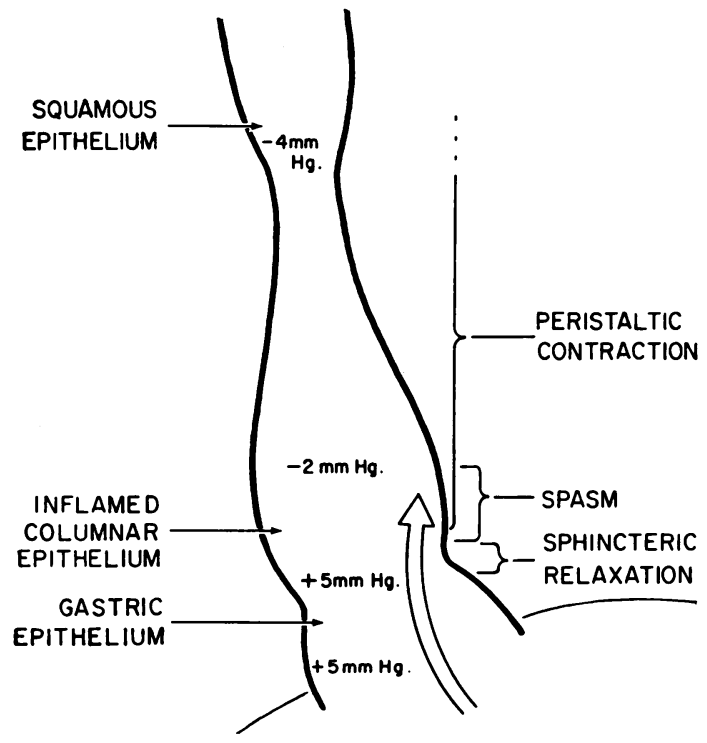

FIG. 8. Resting intraluminal pressures at various levels are as indicated within the outline of the distended distal oesophagus and oesophago-gastric junction. The curved arrow indicates the presence of reflux. 'Spasm' is shown as most marked immediately proximal to the sphincteric area. elevation at all three recording sites (Fig. 6). During this manoeuvre, the patient was instructed not to strain in order to avoid any Valsalva effect. The immediate and maintained transmission of small increases in pressure in this fashion is consistent with the absence of any pressure barrier to reflux (Schenk and Frederickson, 1959; Smiddy and Atkinson, 1960).

While the motor phenomena described above could be easily recognized, on occasion a variety of abnormal motor phenomena were also recorded from the columnarlined portion of the oesophagus. Swallowing occasionally evoked a mixture of peristaltic and non-peristaltic contractions (Fig. 7). Some of the non-peristaltic contractions were repetitive. 'Spasm' waves of greater than twice normal duration and amplitude were registered most prominently at $37 \mathrm{~cm}$. from the incisor teeth.

A summary of the radiological, oesophagoscopic, and manometric findings is shown in Fig. 8 in diagrammatic fashion.

\section{DISCUSSION}

In this case of the Barrett syndrome, the demonstration of a continuous peristaltic wave in response to swallowing down to a small hernial sac clearly indicated that the columnar-lined segment had the motor characteristics of the body of the oesophagus. There was no discontinuity between the squamous and columnar-lined portions. The evidence also indicated that the terminal portion of the columnarlined segment was the location of the sphincteric area as would be anticipated if the columnar-lined segment functioned as oesophagus. The nonperistaltic, repetitive and heightened contractions in the columnar-lined segment are presumably the result of reflux and oesophagitis (Texter et al., 1959).

\section{REFERENCES}

Allison, P. R., and Johnstone, A. S. (1953). The oesophagus lined with gastric mucous membrane. Thorax, 8, 87-101.

Atkinson, M., Edwards, D. A. W., Honour, A. J., and Rowlands, E. B. (1957). The oesophagogastric sphincter in hiatus hernia. Lancet, 2, 1138-42.

Barrett, N. R. (1950). Chronic peptic ulcer of the oesophagus and 'oesophagitis'. Brit. J. Surg., 38, 175-182.

- (1960). Benign stricture of the lower oesophagus. Proc. roy. Soc. Med., 53, 399-402.

Goldman, M. C., and Beckman, R. C. (1960). Barrett syndrome. Gastroenterology, 39, 104-110.

Moersch, R. N., Ellis, F. H. Jr., and McDonald, J. R. (1959). Pathologic changes occurring in severe reflux esophagitis. Surg. Gynec. Obstet., 108, 476-484.

Schenk, E. A., and Frederickson, E. L. (1959). Cardiac and cricopharyngeal sphincter thresholds in the cat. Amer. J. Physiol., 197, 743-746.

Smiddy, F. G., and Atkinson, M. (1960). Mechanisms preventing gastro-oesophageal reflux in the dog. Brit. J. Surg., 47, 680-687.

Som, M. L., and Wolf, B. S. (1956). Peptic ulcer of the esophagus and esophagitis in gastric-lined esophagus. J. Amer. med. Ass., 162, 641-644.

Texter, E. C. Jr., Lazar, H. P., Puletti, E. J., and Van trappen, G. (1959). The characteristic pattern of esophageal dysfunction due to hiatus hernia demonstrated by fluorocinematography and simultaneous pressure recording (Abstract). J. clin. Invest., 38, 1048.

Wolf, B. S., and Cohen, B. R.. (1961). Radiologic localization of the esophageal hiatus as determined by intraluminal pressure measurements. Radiology, 76, 903-910. 